\title{
Promoting Culture of Sharing through Teacher Professional Development
}

\author{
Ajay Pinjani, Aamna Pasha, Ali Bijani, Asad Ali Aslam \\ Aga Khan University Examination Board, Pakistan
}

\begin{abstract}
This paper closely looks at a professional development structure (Annual Teacher Meeting) in which schools, across different regions of Pakistan, affiliated with Aga Khan University Examination Board's Middle School Programme, come together for a workshop. In the academic cycle 2015-16, thirtyseven schools participated in fourteen Annual Teachers Meeting sessions conducted in five different cities across the country. All sessions were facilitated by teacher development personnel with the following aims: developing an enriched understanding of the process of project implementation; sharing successes and challenges; strengthening understanding of competency assessment; nurturing an environment of constructive feedback and encouraging a culture of sharing among teachers. The data was gathered through mixed method, including a feedback form and observation by four trainers. Every session concluded with feedback from participants about the structure and significance of the session. Feedback demonstrated that participants saw such platforms as meaningful for sharing good practices from project implementation, and enhancing the understanding of competencies. Through project review, participants engaged in providing constructive feedback highlighting both areas of improvement and aspects they would like to adopt next year. This meeting broadened teacher's perspective regarding other

contexts and provided a safe space to share misconceptions. It was also observed that accepting feedback from other schools was challenging for teachers and stereotypes existed regarding the extent to which they were likely to learn from schools belonging to dissimilar socio-economic class.
\end{abstract}

\section{Introduction}

A home to more than 201 million people [1], Islamic Republic of Pakistan is the world's 6th most populous country. It is mandated in the Constitution of Pakistan for the state to provide free and compulsory education to all children between the ages of 5 and 16. Over the years, Pakistan has joined many key organizations such as the Education For All (EFA) commitment to set targets for the education sector [2]. Unfortunately, the country is still lagging behind its Millennium Development Goals (MDGs). The literacy rate in Pakistan is close to $58 \%$ where male literacy is approximately $70.2 \%$ while female literacy is only

$46.3 \%$. Here being literate is defined as the 'ability to read and understand a simple text in any language' and the ability to 'write a simple letter and perform basic mathematical calculation' [3]. In the recent years, government has also made inconsistent attempts to increase computer literacy. However, currently only $17 \%$ of the population of Pakistan is actually online [4]. "Low literacy, difficult economic conditions, and cultural resistance have limited the proliferation of ICTs in Pakistan.” [5].

To escape the poor quality of public schools, children from middle and lower-middle class are increasingly being sent to second-tier private schools charging moderate fee. These schools, while claiming to be English medium, adopt a mix of languages to teach their students. The linguistically diverse Pakistan has a total of as many as 70 living languages. The national language is Urdu, which is often the second or third language of a large majority of the population. Teachers preferably use their mother tongue or the common language spoken in the region to teach the concepts written in English in the state textbooks. The children are expected to memorize and reproduce what is written in the text book. The result of adopting this outdated pedagogy is that the learning outcomes of students throughout Pakistan are weak. Pakistan's children score poorly in reading and mathematics across all provinces [6]. Additionally, the teachers in private schools are not better qualified than government school teachers. The average teacher of private schools scored $62 \%$ compared to $56 \%$ scored by a public-school teacher on the APTIS test in 2013 .

In the Pakistani educational system, schools conduct their own examinations and promote students from one grade to the next until Grade 8. Grade 9 onwards, students appear for external examinations that take place either at a provincial or federal level and award certification for the same. There are 27 boards operational at regional level alongside 2 international boards that offer examinations at the secondary and higher secondary level. While the international boards are costly, local boards grapple with issues of fairness and reliability. The Aga Khan University Examination Board (AKU-EB) is Pakistan's first private autonomous national examination body established by the Aga Khan 
University in August 2003 in accordance with Ordinance CXIV of the Government of Pakistan. The need for its establishment was felt in light of the lack of affordable, transparent and fair assessments at the secondary (SSC) and higher secondary (HSSC) school certification level. AKU-EB's primary purpose is to improve the quality of education by providing high quality examinations across the country in accordance with the National Curriculum of Pakistan. AKU-EB enrolls students from diverse geographic, ethnic, religious and socio-economic backgrounds across the country. Strong emphasis is placed on concept based learning and students are assessed on their understanding and application of knowledge. The designed syllabi and assessment along with teacher training platforms support, schools in moving away from rote memorization towards, deeper understanding of concepts and the development of higher order cognitive skills. Recognizing the struggle of students and teachers to teach for higher cognitive levels and the dependence on traditional teaching methodologies, a Middle School Programme (MSP) was conceptualized. The purpose of the programme is twofold: the first is the enrichment of content-based learning by offering interdisciplinary and experiential learning environment; the second is the development of a wide range of competencies by offering a broadbased foundation of educational experience. This is premised on the awareness that students of today need to be prepared to thrive in a world that is consistently changing. Together, the vision was to help develop lifelong learners by encouraging students to approach learning differently, recognize linkages across disciplines and journey from conceptual knowledge to its understanding and application. Each school opting for Middle School Programme receives a set of six interdisciplinary projects for each grade. These project tasks are designed by AKU-EB and are based on middle school syllabi drawn from the National Curriculum of Pakistan. Schools opt for any 4 projects, to be completed in one academic year, that align with their syllabi. Teachers assess the academic quality of students' project work and the competencies demonstrated in task completion using a standard rubric developed by AKU-EB. Teachers of all schools affiliating with AKU-EB for the programme are provided orientation training at the beginning of the academic year to familiarize them with project implementation and competency assessment.

The professional development intervention that we wanted to design needed to enhance teachers understanding of the Middle School Programme. This was a twofold task: strengthening teachers' implementation of project based learning and enhancing their understanding of competency assessment. Given that project based learning was a new pedagogy for a majority of teachers in Pakistan, we anticipated gaps in implementation. Additionally, we recognized that understanding of what competencies are and how they are observed and assessed would be challenging for teachers as the use of a rubric is also a relatively new form of assessment. This realization was heightened during the orientation of teachers to the programme and throughout the year while offering ongoing support. The second core aim was therefore to further develop their skill of observational assessment. Aside from the programmatic intent, the teacher development team recognized that in order to continue to improve and enhance the projects developed and to ensure that the optimum opportunity for competency development is being provided, it is necessary for us to be informed of the challenges experienced by teachers across different contexts. Given the multiplicity that exists from one school to another in Pakistan, in terms of resource availability, teacher proficiency, acceptability of new methodology and student readiness, we considered it important to cognize the challenges that could further enrich our support to the schools, hence the Annual Teacher Meeting acted as a medium for this purpose. "The conditions in which teachers work matter a great deal to them and, ultimately, to their students." In a research conducted to explore the relationship between context of a school and its impact on teacher's professional satisfaction and student achievement, it was concluded that providing a supportive culture in which teachers can work appears to contribute to improved student achievement. [7] Lastly, we recognized that in Pakistan limited opportunity exists for teachers to meet teachers of other schools, to look at the work of students that they do not directly teach, to share their experiences across diverse contexts, and to collectively have a dialogue on a common content that they individually worked on. Thus we wanted to take the initiative of providing a platform

that encourages such conversations and sows the seed for developing a culture of sharing amongst schools. A research exploring the experiences of Singaporean teachers as a result of sharing knowledge among one another, found that through sharing with colleagues helped them increase their own learning and once acknowledged, they felt their knowledge was also worthy of sharing. It was observed that when teachers share an idea or their way of teaching with one another, the practice of penning down their ideas helped them improve that idea, and sharing of insights though dialogue further enriched this process [8]. Another study reaffirmed that teachers want to know what colleagues are currently thinking and learn about the methods and approaches that are being used [9]. While benefits reaped from creating platforms for teachers to meet within a school have been significantly acknowledged, it has been stressed that 'socialization should not be limited to one school but teachers from different schools should come together and share their knowledge'[8]. A study on school 
improvement shared its findings that teachers are more able to implement new ideas within the context of supportive collaborative relationships. Such collaborations strengthen resolve, give space for sharing of common frustrations and allow greater coordination and consistency of teaching approaches [10].

In order to achieve our objectives, it was decided that three schools be invited together to an Annual Teacher Meeting (ATM). Bringing schools together was seen to offer multiple benefits; foremost, it would allow teachers to come together to share their students work and network with each other. Secondly, it would provide the platform for teachers to share their experiences and challenges of project implementation, and how they facilitated the process. The number of schools invited to one meeting was limited to three, as what was essential was that the group size allows active participation and sharing along with the opportunity to see each other's students work in depth. A project review exercise was designed to meet the objective of having teachers look at student work from other schools, reflect on their students' project implementation vis a vis others, and participate in a dialogue on similarities and differences. The aims of education evolve depending on the demands of era. According to Kress "the previous era

had required an education for stability, the coming era requires an education for instability" [11]. As a result competency development has become one of the dominant goals of education. Since teachers are responsible for operating educational system they need to explore and understand these competencies before creating an environment to inculcate the same in their students.

In order to improve teachers understanding of competencies a number of clips of students working on a single project were enacted and recorded for the purpose of ATM. These videos were displayed and teachers were asked to use the rubric to score the three students appearing in the videos, on each competency. Once filled and recorded, the variations in the scores are shared and collectively discussed to further enhance the teachers' understanding of the competencies and their observational skills. Throughout the meeting, different aspects of the middle school programme are explored by encouraging participants to share contextual strengths and limitations, when they experienced the implementation of projects in their classroom.

\section{Methodology and Results}

At the end of each Annual Teacher Meeting, participants were given a feedback form containing qualitative and quantitative questions to evaluate the meeting in terms of its objectives, structure, trainer's effectiveness, content quality and other facilities.
Each participant submitted their anonymous feedback on the meeting. In addition the observation of the 4 trainers who executed the ATMs individually shared their observation on the ATM which was later analyzed through open coding. Overall, 14 ATMs were conducted in 5 different cities. A total of 241 participants including teachers, coordinators and principals from 37 schools across Pakistan gave their feedback in the Annual Teacher Meetings (ATMs) conducted for the Middle School Programme cycle 2015-2016. The Figures below analyze the data gathered from three questions asked in the feedback form by all participants. The participants were asked if the ATM helped them to better understand the Middle School

Programme (MSP). $66 \%$ of the teachers said that the meetings successfully built up on their knowledge of the MSP while remaining 34\% felt it was 'somewhat' or at least 'a little' helpful (see Figure 1). Throughout the ATM participants received an opportunity to voice out their experiences and opinions about every aspect of MSP, and the facilitators consciously attempted to identify areas of misconceptions and timely counter them in study manner through discussion and reflection. This open dialogue on project implementation could be a significant reason due to which, a majority of the participants considered ATM helpful in better conceptualizing the programme and its purpose.

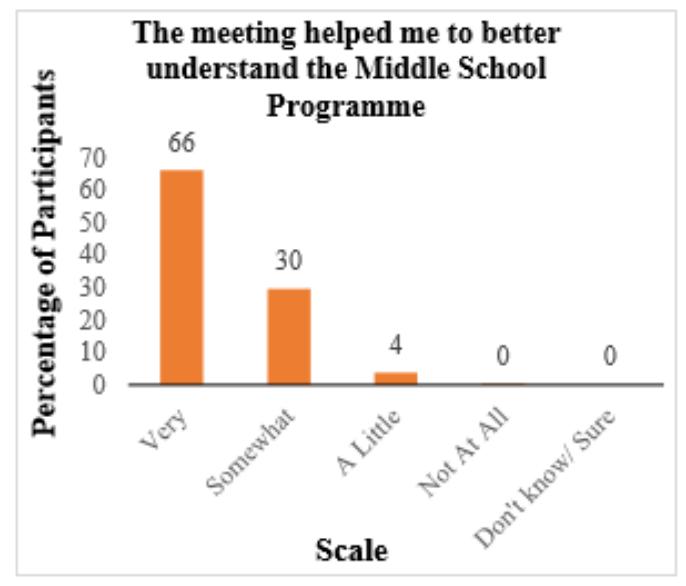

Figure 1. Value of the meeting to better understand the Middle School Programme

The participants were also asked if they found the meeting engaging. $50 \%$ of the participants said that the meeting was 'very' engaging. Another $42 \%$ also found the meeting 'somewhat' engaging. In the context of Pakistan, it is often a rare opportunity for teachers to interact with other school teachers, especially for a same project that has been executed by all schools attending a workshop or a meeting. Therefore, what AKU-EB MSP provided the teachers, was a unique experience coupled with a professional 
development session that would contribute to their teaching and career growth. In addition, at many ATM's the participating schools differed not only in area but also in the socio-economic and ethnic backgrounds each school represented. Hence, for some teachers, they received a platform to learn about not only the programme implementation but also interact with diverse cultural contexts in which education takes place in Pakistan.

The format of the meeting could also act as a contributor to the high level of engagement experienced by participants. Teachers watched video clips in which the trainers enacted students implementing a project. As a result, there was engagement as well as reflective debate, because in many situations the variation in scores for the same competency varied leading to conversations and arguments taking place to and fro.

Overall, the participants were excited to see other schools, observe their work and interact with them in a highly engaging environment (see Figure 2).

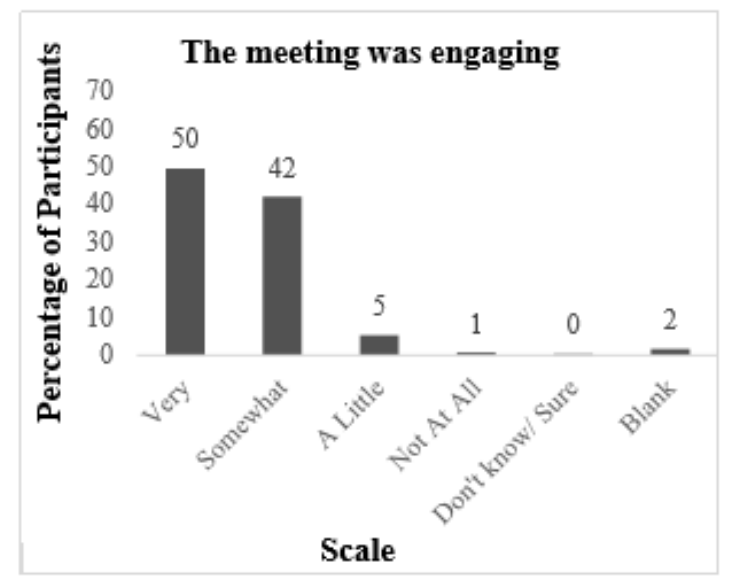

Figure 2. Participants' opinion on whether the meeting was engaging

When asked if they were able to take away any learning from the way other schools implemented their projects, the response was varying. As Figure 3 below demonstrates, more than $50 \%$ of the teachers felt they were 'somewhat' able to learn from the implementation of projects by other schools. The remaining participants either learned a lot or too little. This observation was interesting to interpret since this was the first time the Annual Teacher Meeting was being held in the described manner. For multiple schools of varying demographics to come together, interact and learn from each other was a new experience and it was only gradually that they settled in. It took time for them to understand and accept their shortcomings and learn from the experiences of others. Participants, nonetheless, appreciated the effort done by other schools and shared how the meeting enhanced their understanding of conceptual learning and reaffirmed the importance of a studentcentered approach to learning.

Some common factors, emerging from different studies, that encourage teachers to share their knowledge with one another include self-efficacy, trust, enjoyment in helping others, and collective cognitive responsibility [12], [13], [14], [15].

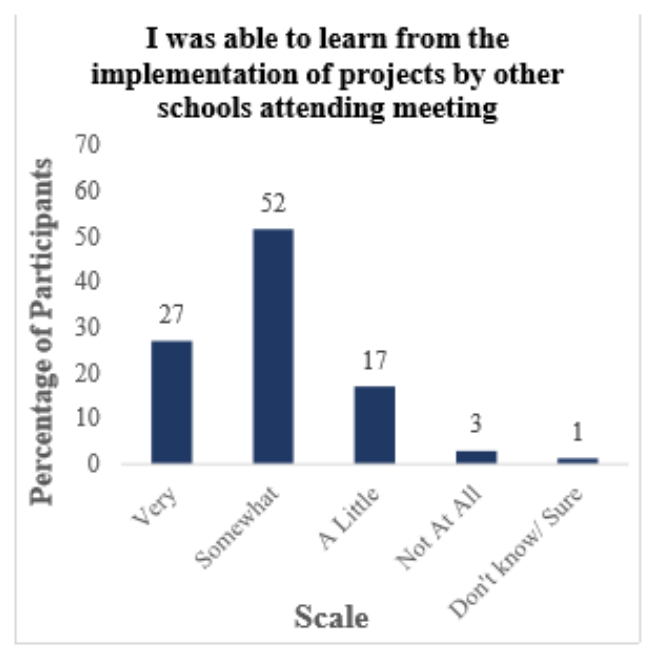

Figure 3. Meeting as a platform to learn from participants from other schools

Our analysis of all meetings collectively demonstrated that when a conducive environment is created, the aforementioned factors do come to surface and make the process of sharing and interaction more lively and meaningful. Simultaneously, studies have stated that one of the major hurdles is the fear of criticism, experienced by the teacher, which then leads to reluctance in sharing [7].

\subsection{Trainers' Observation}

The trainers' observed that the structure of the ATM provided a unique opportunity of focused group interaction with teachers from other schools. Additionally, gaps in implementation were recognized through an exchange of experiences which was enriched by the structure of the ATM. AKU-EB became a facilitator in such a setting rather than an influential expert. This had another advantage of providing a safe space to share misconceptions. Teachers seemed to be more comfortable to open up with other teachers outside of their school. This could be because often there is a strong hierarchy that exists within schools. Teachers are unable to share problems with their coordinators or school principal due to fear of being questioned on their capabilities or fear of being reprimanded for mistakes made. Meeting teachers brought forward a lot of queries and challenges which may not have been shared otherwise. Additionally, teachers received exposure 
of broader perspectives by meeting those outside of their school. When using visual aids to clarify understanding of the rubric, some teachers' observation was coloured by the context in which they worked which was interesting for both the trainer and other teachers. This also allowed the Teacher Development team to become aware of the common and contextual challenges of project implementation. Very interestingly, with regard to student work, the significance of originality (student's own work) and competency development was accepted regardless of contextual limitations. Two other interesting observations surfaced from the meeting. It was noticed that teachers showed substantial resistance when teachers from other schools gave feedback on implementation of projects after the project review exercise. Teachers were less receptive of constructive feedback. This could be because such a platform and exercise, teachers have not been exposed to before. It was also noticed that a culture of competition and socio-economic divide influenced the way in which schools perceived one another. On occasions some schools shared pre-conceived assumptions, making statements that they do not expect to learn much from a school due to their socio-economic background, size or years of establishment. This mindset is essential to shake and could explain the resistance to feedback as mentioned earlier.

\section{Conclusion}

These meetings initiated discussions that the teacher development team is keen to further explore. We learnt that creating a safe space for teachers plays an instrumental role in bringing forth misconceptions and true opinions of teachers. Although it was challenging to accept critique from participating schools, the meeting did act as the first step towards developing a culture of sharing. We believe that as this culture strengthens it is likely that stereotypes that exists across schools will also decrease and the value of participating in constructive dialogue will be widely acknowledged. It was also recognized that more professional development and capacity building initiatives are required to assist teachers in comprehending and practicing the role of a facilitator, leaving the comfort zone of instructive classes aside.

\section{Acknowledgements}

The authors would like to thank Misbah Dawood, Associate Teacher Development, for her invaluable assistance throughout.

\section{References}

[1] The World Factbook - Central Intelligence Agency. (2017), Cia.gov., https://www.cia.gov/library/publications /the-worldfactbook/geos/pk.html (Access Date: 16 June, 2017).

[2] Hussain, A., (2015). 'Education System of Pakistan: Issues, Problems and Solutions', http://www.ipripak.org/ category/ipri-reviews/ (Access Date: 13 June, 2017).

[3] Sheikh, A., (2017). 'Govt redefines literacy for count The Express Tribune. The Express Tribune, https://tribun e.com.pk/story/1341159/govt-redefinesliteracy-count/ (Access Date: 16 June, 2017).

[4] Peña-López, I., (2016). 'World development report 2016: Digital dividends.' World Bank; http://documents. world-bank.org/urated/en/896971468194972881/ pdf/102725-PUB-Replacement-PUBLIC.pdf.

[5] Pakistan Country Report 2015. (2017) (23rd ed.). Freedom House; https://freedomhouse.org/report/ freedomnet/2015/pakistan (Access Date: 13 June, 2017).

[6] 'The State of Education in Pakistan.' (2017) Alif Ailaan; https://d3n8a8pro7vhmx.cloudfront.net/alifailaan/pages/ 496/attachments/original/1473162927/The_State_of_Ed ucation_in_Pakistan.pdf?1473162927 (Access Date: 16 June, 2017).

[7] Moore, S., Matthew, A. and Papay, J., How Context Matters in High- Need Schools: The Effects of Teachers' Working Conditions on Their Professional Satisfaction and Their Students' Achievement: Teachers College Record; http://www.tcrecord.org/Content.asp?ContentId=16685 (Access Date: 13 June, 2017).

[8] Chaudhry, A., and Sivakamasundari, B., (2004). Perceptions of Teachers about Knowledge Sharing in Schools. Singapore: Idea Group Publishing; http://www.irma-international.org/viewtitle/32334/ (Access Date: 16 June, 2017).

[9] McAndrew, P., Clow, D., Taylor, J., and Aczel, J., (2004). The evolutionary design of a Knowledge Network to support knowledge management and sharing for lifelong learning. British Journal Of Educational Technology, 35(6), 739-746. http://dx.doi.org/10.1111/j.1467-8535.2004. 00431.x.

[10] Harris, A., (2002). School Improvement: What's In It For Schools. London: RoutledgeFalmer.

[11] Kress, G., (2000). A Curriculum for the Future. Cambridge Journal Of Education, 30(1), 133-145. http://www.itslifejimbutnotasweknowit.org.uk/files/CPL HE/CJEKressCurric.pdf.

[12] Bandura, A., (1997). Self-Efficacy: The exercise of control. New York: W. H. Freeman.

[13] Scardamalia, M., (2002). Scardamalia, M. (2002). Collective Cognitive Responsibility for the Advancement of Knowledge. In Liberal education in a knowledge society (pp. 67-98). Chicago: Open Court; http://ikit.org/fulltext/ inpressCollectiveCog.pdf.

[14] Kankanhalli, A., C. Y. Tan, B., and Wei, K., (2005). Contributing Knowledge to Electronic Knowledge 
Repositories: An Empirical Investigation. MIS Quarterly, 29(1), 113-143; http://misq.org/contributingknowledge-toelectronic-knowledge-repositories-anempirical-investigation.html.

[15] Hsu, M., Ju, T., Yen, C., and Chang, C., (2007). Knowledge sharing behavior in virtual communities: The relationship between trust, selfefficacy, and outcome expectations. International Journal of Human-Computer Studies, 65(2), 153-169. http://dx.doi.org/10.1016/j.ijhcs. 